\title{
An Appreciation to the 1992 Reviewers
}

The strength of a journalistic peer review process lies with the breadth of knowledge and experience of the referees who assess each manuscript. Each submission to Pediatric Neurosurgery is read by at least 4 reviewers and where the topic is particularly complex or crosses disciplines, or where there is dispute from the initial panel about a paper's worthiness, additional opinions are sought. The masthead lists the reviewers assigned to the surgical papers. Each referee has been selected for his/her particular area of expertise (in addition to dedication to the process). The Journal is most grateful for the time and thought which these surgeons have given during 1992, a landmark year for the publication.

There are several other individuals who also deserve recognition for their efforts during the same time. The Editorial Board extends to each its appreciation with the hope that if the occasion should arise again, their advice may be sought.

Dr. I. Richmond Abbott, New York, N.Y. Dr. Jeffrey Allen, New York, N.Y. Dr. A. Leland Albright, Pittsburgh, Pa. Dr. Patricia E. Burrows, Boston, Mass. Dr. Jeffrey Cohen, Pittsburgh, Pa. Dr. Ziad Deeb, Pittsburgh, Pa. Dr. Mark Greenberg, Toronto, Ont. Dr. John Kennderdell, Pittsburgh, Pa. Dr. J. Parker Mickle, Gainesville, Fla. Dr. Andrew D. Parent, Jackson, Miss. Dr. Matthew R. Quigley, Pittsburgh, Pa. Dr. Deborah Rotenstein, Pittsburgh, Pa. Dr. Tae Sung Park, St. Louis, Mo. Prof. Michael Salter, Toronto, Ont. Dr. Paul Steinbok, Vancouver, B.C. Dr. Bruce B. Storrs, Charleston, S.C. Dr. Leslie N. Sutton, Philadelphia, Pa. Dr. Donald Younkin, Philadelphia, Pa. 